\title{
Hypoglycaemia in children aged 1 month to 17 years admitted to the children's emergency room of Nnamdi Azikiwe University Teaching Hospital, Nnewi, Nigeria
}

\author{
N C Azuka, ${ }^{1}$ FWACP (Paed); J O Chukwuka, ${ }^{2}$ FMCPaed; J C Ebenebe, ${ }^{2}$ FWACP (Paed); O C Ofiaeli, ${ }^{2}$ FMCPaed \\ ${ }^{1}$ Alder Hey Children's NHS Foundation Trust, Liverpool, United Kingdom; formerly Senior Registrar in Paediatrics, Nnamdi Azikiwe University \\ Teaching Hospital, Nnewi, Nigeria \\ ${ }^{2}$ Nnamdi Azikiwe University and Nnamdi Azikiwe University Teaching Hospital, Nnewi, Nigeria
}

Corresponding author: N C Azuka (Nwaizu.Azuka@alderhey.nhs.uk)

\begin{abstract}
Background. Hypoglycaemia is a common presenting feature of illness among children admitted with various conditions into the paediatric emergency room.

Objective. To determine the prevalence of hypoglycaemia among children admitted into a Nigerian teaching hospital, identify some of its associated factors and assess its relationship to patient outcome.

Methods. In this cross-sectional study, 388 children were consecutively recruited. Their sociodemographic characteristics, clinical features and management outcome were obtained. Plasma glucose was measured using the glucose oxidase method and classified as hypoglycaemia $(<3.4 \mathrm{mmol} / \mathrm{L})$, low glycaemia $(3.4-<4.4 \mathrm{mmol} / \mathrm{L})$, normoglycaemia $(4.4-7.7 \mathrm{mmol} / \mathrm{L})$ and hyperglycaemia $(\geq 7.8 \mathrm{mmol} / \mathrm{L})$.

Results. Hypoglycaemia occurred in $50(12.9 \%)$ subjects, while $55(14.2 \%)$ had low glycaemia. At bivariate analysis, hypoglycaemia was associated with age $(p=0.012), \geq 6$ hours from the last meal $(p=0.004)$, medication use before presentation $(p=0.014)$ and some markers of illness severity such as loss of consciousness $(p<0.001)$, respiratory distress $(p=0.004)$, dehydration $(p=0.002)$, shock $(p=0.004)$, and hypoxia ( $p=0.001$ ). After logistic regression, a time $\geq 6$ hours from last meal (adjusted odds ratio (aOR) 2.98 ; $95 \%$ confidence interval $(\mathrm{CI})$ 1.27 - 6.98), hypoxia (aOR 3.10; 95\% CI 1.39 - 6.90), and passage of watery stools (aOR 2.92; 95\% CI 1.26 - 6.78) were associated with hypoglycaemia. Hypoglycaemic subjects were 2.9 times more likely to die than normoglycaemic ones $(p<0.001)$ but this association was lost at multivariable analysis.

Conclusion. Hypoglycaemia complicates common childhood illnesses and may be associated with poorer outcomes. Plasma glucose measurement and subsequent appropriate action should be core parts of the immediate management of ill children.
\end{abstract}

S Afr J Child Health 2021;15(1):25-32. https://doi.org/10.7196/SAJCH.2020.v15i1.1761

Glucose, a monosaccharide, is the most important carbohydrate and the major metabolic fuel in humans. ${ }^{[1]}$ The maintenance of blood glucose is a finely regulated homeostatic mechanism which involves the liver, extrahepatic tissues such as muscles and adipose tissue, and several hormones such as glucagon, growth hormone and insulin. ${ }^{[1]}$

In critical childhood illnesses, a defect in one or more of these complex interactions that regulate blood glucose results in hypoglycaemia. ${ }^{[2]}$ A rapidly decreasing hepatic glycogen store, further worsened by an inadequate supply of gluconeogenic substrates, especially in conditions with increased catabolism such as bacterial infections, reduces the rate at which glucose appears in the blood, leading to the development of hypoglycaemia. ${ }^{[3]}$

Hypoglycaemia is a common presenting feature among children admitted with various conditions to the paediatric emergency room or intensive care unit. ${ }^{[4-13]}$ Non-African studies found that it complicates as much as $9.7-18.6 \%$ of childhood illnesses. ${ }^{[8,9]}$ In some African countries, prevalence of hypoglycaemia among ill children ranges from $3.1-7.3 \%,{ }^{[4,7]}$ while in Nigeria it is as high as $5.1-20.7 \% .^{[5,6,10-13]}$

Infants and younger children are more susceptible to hypoglycaemia than adults owing to a lower glycogen store, a substantially smaller muscle bulk relative to body mass, and greater glucose requirements per unit of body mass. ${ }^{[2,3]}$ Other risk factors for the development of hypoglycaemia include a time $>4-12$ hours from the last meal, ${ }^{[-7,72]}$ infectious diseases ${ }^{[5,10]}$ and some disease severity markers such as deep coma and severe malnutrition. ${ }^{[5,7]}$

Hypoglycaemia presents with nonspecific symptoms, usually classified as adrenergic and neuroglycopenic symptoms. ${ }^{[2]}$ Hypoglycaemia, especially when recurrent or longstanding, can result in mental retardation, recurrent seizures or both. ${ }^{[2]}$ Hypoglycaemia has been found to significantly increase morbidity and mortality among severely ill children both in Africa and North America. ${ }^{[4-6,8,11-13]}$

The majority of Nigerian studies on the prevalence rate and pattern of hypoglycaemia among children admitted into the emergency room were at cut-off values of blood glucose concentration $<2.2 \mathrm{mmol} / \mathrm{L}$ or plasma glucose concentration $<2.5 \mathrm{mmol} / \mathrm{L}$, which were acceptable at the time as the definition for hypoglycaemia but at which point complications, especially neurological sequelae, may have set in. ${ }^{[5,6,10-12]}$ Concerns to avoid these complications arising from hypoglycaemia, especially neurological sequelae, have caused the bar to be raised in the definition of hypoglycaemia, to blood glucose $<3.1 \mathrm{mmol} / \mathrm{L}(55 \mathrm{mg} / \mathrm{dL}),{ }^{[2]}$ and plasma glucose $<3.4-3.5 \mathrm{mmol} / \mathrm{L}$ $(60.5-63.3 \mathrm{mg} / \mathrm{dL})^{[2]}$

The present study sought to determine the prevalence of hypoglycaemia among children admitted into the children's emergency room of a typical Nigerian teaching hospital, at a plasma glucose cut-off value $<3.4 \mathrm{mmol} / \mathrm{L}$, identify some of its associated 
factors and relate the plasma glucose concentrations to the outcome of management. This study used the current plasma glucose cut-off in the definition of hypoglycaemia, which was higher than that used in most previous Nigerian studies, to demonstrate how much of a problem hypoglycaemia was among ill children.

\section{Methods}

This cross-sectional study was conducted at the Children's Emergency Room (CHER) of the Nnamdi Azikiwe University Teaching Hospital (NAUTH), Nnewi, Anambra State, Nigeria, over a 7-month period (September 2016 - March 2017). The CHER is a 10-bed ward which admits all children, except neonates, with medical and surgical emergencies such as severe malaria, gastroenteritis with dehydration, pneumonia, meningitis, sepsis/severe sepsis, and intussusception, presenting to the hospital. They are stabilised usually within 48 hours and transferred to the children's ward for continued care. Neonates do not pass through this unit but are admitted directly to the special-care baby unit. This hospital offers specialised healthcare services, which include paediatric services, to inhabitants of Anambra State and neighbouring states.

The study population included children aged 1 month to 17 years, admitted into the CHER of NAUTH, who were met at presentation and whose parents gave consent. They were consecutively recruited until the sample size was met. Known diabetics were excluded. The minimum sample size was calculated as 388 subjects, based on the sample size formula for a proportion, ${ }^{[14]}$ using a precision of $3 \%$ at $95 \%$ confidence interval (CI) and a prevalence of $10.1 \%$ from the study by Okoronkwo et al. ${ }^{[5]}$ This was a similar study conducted eight years earlier.

Ethical approval was obtained from the Ethics Review Committee of the institution and permission obtained from the Head, Department of Paediatrics, of the institution. Individual written informed consent was obtained from parents/caregivers of the subjects and assent from children $\geq 6$ years.

A study pro forma was used to record information on sociodemographic characteristics, clinical symptoms and signs, anthropometry, and the outcome of management. In particular, symptoms and signs suggesting severe illness were sought and recorded. ${ }^{[15]}$ Dehydration was assessed based on physical signs of dehydration as described in the World Health Organization's (WHO) manual on treatment of diarrhoea in children. ${ }^{[16]}$ Hypoxia was defined as a pulse oximeter reading $\leq 94 \%$. ${ }^{[17]}$ Subjects were classed as being in shock if they had tachycardia, cool extremities, delayed capillary refill, mottled or pale skin, and effortless tachycardia. ${ }^{[18]}$ Respiratory distress was defined by the presence of tachypnoea with nasal flaring and intercostal, subcostal and sternal recessions. ${ }^{[19]}$

While maintaining asepsis, $2 \mathrm{~mL}$ of blood was collected from the subject into a fluoride-oxalate bottle before commencement of treatment. To screen for hypoglycaemia at the bedside, a drop of blood from the fluoride-oxalate container was used to measure the plasma glucose concentration, using the Accuchek Performer glucometer (Roche Diagnostics, Germany). This screening was to ensure that those with hypoglycaemia received immediate attention/treatment, to avoid complications. The rest of the blood sample was used for plasma glucose measurement, using the glucose oxidase method, at the hospital's chemical pathology laboratory. The plasma glucose measurement via the glucose oxidase method was used to assess hypoglycaemia in this study. All patients received standard care for their various illnesses.

Data were entered and analysed using the Statistical Package for Social Sciences (SPSS) version 20 (IBM Corp., USA). Socioeconomic status was determined using Oyedeji's classification. ${ }^{[20]}$ Nutritional status was classified into normal, moderate undernutrition, severe undernutrition and overnutrition, according to the WHO Global Database on Child Growth and Malnutrition using weight-for-height (wasting), height-for-age (stunting) and weight-for-age (underweight) parameters according to standard deviation (SD) scores. ${ }^{[21]}$ Centers for Disease Control (CDC) charts were used to determine $Z$-scores. Plasma glucose was classified as hypoglycaemia $(<3.4 \mathrm{mmol} / \mathrm{L})_{,}{ }^{[2]}$ low glycaemia $(3.4-<4.4 \mathrm{mmol} / \mathrm{L}){ }^{[4]}$ normal $(4.4-7.7 \mathrm{mmol} / \mathrm{L})^{[22]}$ and hyperglycaemia $(\geq 7.8 \mathrm{mmol} / \mathrm{L}){ }^{[23]}$ Relevant proportions were calculated, and the $\chi^{2}$ test was done for the association between qualitative variables and categorical plasma glucose concentration. The association between hypoglycaemia and outcome of illness was explored by cross-tabulation and the $\chi^{2}$ test. Multivariate logistic regressions were carried out to adjust for confounders (factors associated with hypoglycaemia) at bivariate analysis with a $p$-value $\leq 0.10$ except if clinically or biologically related to another factor, in which case only the factor with stronger association was included in the model to avoid multicollinearity of the association between selected independent variables and hypoglycaemia as well as confounders of the association between hypoglycaemia and illness outcome.

\section{Results}

A total of 388 children aged 1 month to 17 years were recruited over a 7-month period (September 2016 - March 2017). There were $244(62.9 \%)$ boys, with a male:female ratio of $1.7: 1$. The median age was 21 months (interquartile range (IQR) 8.0 - 73.8 months). The under-5 age group (269) comprised a large proportion of the subjects, at $69.3 \%$. Subjects from the high socioeconomic class, comprising Classes I - III, constituted 230 (59.3\%) of the study population (Table 1). The subjects' diagnoses are shown in Table 2.

Of the 388 study subjects, 50 (12.9\%) (95\% CI 9.5 - 16.5\%) were hypoglycaemic, 55 (14.2\%) (95\% CI 11.1 - 17.5\%) had low glycaemia, $239(61.6 \%)$ (95\% CI 56.4 - 66.2\%) were normoglycaemic, and 44 (11.3\%) (95\% CI 8.2 - 14.7\%) were hyperglycaemic.

Table 3 shows the factors associated with hypoglycaemia. At bivariate analysis, there was a statistically significant age-related trend in the occurrence of hypoglycaemia, with the highest prevalence of $23 \%(n=29 / 126)$ among infants and the lowest prevalence of $2.2 \%$

Table 1. Sociodemographic characteristics of subjects

\begin{tabular}{lc}
\hline Variable & $n(\%)$ \\
\hline Age group (months) & $146(37.6)$ \\
$1-12$ & $123(31.7)$ \\
$12-59$ & $68(17.5)$ \\
$60-119$ & $51(13.1)$ \\
$\geq 120$ & \\
Sex & $244(62.9)$ \\
Male & $144(37.1)$ \\
Female & \\
Place of residence & $199(51.3)$ \\
Anambra but outside Nnewi & $162(41.8)$ \\
Nnewi & $21(5.4)$ \\
Other states & $6(1.5)$ \\
Missing values & \\
Socioeconomic status ${ }^{*}$ & $120(59.3)$ \\
High & $158(40.7)$ \\
Low & \\
${ }^{*}$ Oyedeji's classification: high $=$ classes I - III; low = classes IV and V.
\end{tabular}


Table 2. Diagnosis of patients

\begin{tabular}{|c|c|}
\hline Diagnosis & $N(\%)^{*}$ \\
\hline Malaria & $81(20.9)$ \\
\hline Severe malaria, $n$ & 63 \\
\hline Acute uncomplicated, $n$ & 18 \\
\hline Multisystemic infections & $76(19.6)$ \\
\hline Sepsis, $n$ & 49 \\
\hline Severe sepsis ${ }^{\dagger}, n$ & 27 \\
\hline Gastroenteritis & $47(12.1)$ \\
\hline Surgical conditions & $46(11.9)$ \\
\hline Intussusception, $n$ & 25 \\
\hline Intestinal obstruction, $n$ & 7 \\
\hline Obstructed hernia, $n$ & 4 \\
\hline $\begin{array}{l}\text { Other (enterocutaneous fistula, complicated, } n \\
\text { ovarian cyst, intra-abdominal abscess) }\end{array}$ & 4 \\
\hline Appendicitis, $n$ & 3 \\
\hline $\begin{array}{l}\text { Biliary atresia, hypertrophic pyloric stenosis, } \\
\text { Hirschsprung's disease ( } 1 \text { each), } n\end{array}$ & 3 \\
\hline Respiratory conditions & $38(9.8)$ \\
\hline Unspecified acute respiratory infection, $n$ & 19 \\
\hline Pneumonia, $n$ & 12 \\
\hline Pharyngotonsilitis, $n$ & 4 \\
\hline $\begin{array}{l}\text { Bronchiolitis, pharyngeal abscess, epiglottitis } \\
\text { ( } 1 \text { each), } n\end{array}$ & 3 \\
\hline Meningitis & $13(3.3)$ \\
\hline Protein energy malnutrition & $13(3.3)$ \\
\hline Renal conditions & $9(2.3)$ \\
\hline $\begin{array}{l}\text { Acute glomerulonephritis, chronic kidney disease, } \\
\text { bladder outlet obstruction secondary to PUV, } \\
\text { urolithiasis ( } 1 \text { each), } n\end{array}$ & 4 \\
\hline Nephrotic syndrome, $n$ & 3 \\
\hline Acute renal failure, $n$ & 2 \\
\hline Complications of paediatric HIV/AIDS & $8(2.1)$ \\
\hline Seizures & $8(2.1)$ \\
\hline Febrile convulsion, $n$ & 4 \\
\hline Seizure disorders, $n$ & 3 \\
\hline Status epilepticus, $n$ & 1 \\
\hline Malignancies & $7(1.8)$ \\
\hline Sickle cell crisis & $7(1.8)$ \\
\hline Trauma & $5(1.3)$ \\
\hline Poisoning & $4(1.0)$ \\
\hline Hydrocephalus & $4(1.0)$ \\
\hline Tuberculosis & $3(0.8)$ \\
\hline Other & $19(4.9)$ \\
\hline Total & $388(100)$ \\
\hline \multicolumn{2}{|c|}{$\begin{array}{l}\text { PUV = posterior urethral valve; HIV/AIDS = human immunodeficiency virus/ } \\
\text { acquired immune deficiency syndrome. } \\
\text { *Unless otherwise specified. } \\
\text { 'Sepsis with organ dysfunction. }\end{array}$} \\
\hline
\end{tabular}

( $n=1 / 46)$ among subjects aged $\geq 10$ years $(p=0.002)$. A time from last meal $\geq 6$ hours before presentation was significantly associated with hypoglycaemia $(p=0.004)$. Use of medication before presentation was also significantly associated with hypoglycaemia $(p=0.014)$. There was no statistically significant association between any of the types of malnutrition and hypoglycaemia. It is noteworthy that of all the patients with malnutrition, none was of the oedematous type. There was no association between use of traditional medications and hypoglycaemia $(p=0.147)$. There was also no significant association between gender, use of glucose-containing fluid prior to presentation, duration of illness before presentation, socioeconomic status and hypoglycaemia.

Loss of consciousness at presentation was associated with hypoglycaemia $(31.5 \%(n=17 / 54)$ v. $11.5 \%(n=33 / 288), p<0.001)$. Respiratory distress was also significantly associated with hypoglycaemia, as subjects with respiratory distress were 2.1 times more likely to have hypoglycaemia than subjects without respiratory distress (22.4\% $(n=26 / 116)$ v. $10.8 \% \quad(n=24 / 222) ; p=0.004)$. A statistically significant association was also found between hydration status and hypoglycaemia, as $40 \%(n=6 / 15)$ of severely dehydrated subjects, $20.4 \%(n=19 / 93)$ of moderately dehydrated subjects, and $10.7 \%(n=25 / 234)$ of those who were not dehydrated were hypoglycaemic $(p=0.002)$. Patients with shock were more likely to have hypoglycaemia than those without shock $(43.8 \% \quad(n=7 / 16)$ v. $13.1 \%(n=43 / 327) ; p=0.004)$. Twenty-three subjects $(32.9 \%$ of hypoxaemic subjects) and 21 subjects (9.5\% of non-hypoxaemic subjects) had hypoglycaemia $(p<0.001)$. Subjects with a history of loss of consciousness, fever, fast breathing and watery stools were more likely than subjects without these symptoms to have hypoglycaemia; the $p$-values for the associations were $0.006,0.007$, 0.013 and $<0.001$, respectively (Table 4 ). There was no significant association between hypoglycaemia and other clinical features such as convulsions, tachypnoea, temperature $>38.5^{\circ} \mathrm{C}$ at presentation, vomiting, and weakness (Table 4).

The time from last meal to presentation remained significantly associated with hypoglycaemia after adjustment for confounding. The subjects whose last meal was $\geq 6$ hours prior to presentation were 2.98 times more likely to have hypoglycaemia compared with subjects who had eaten $<6$ hours before presentation (adjusted odds ratio (aOR) 2.98; 95\% CI $1.27-6.98 ; p=0.012$ ). Hypoxaemia at presentation was significantly associated with hypoglycaemia (aOR $3.10,95 \%$ CI $1.39-6.90 ; p=0.006$ ), as was a history of passage of watery stools ( $\mathrm{aOR} 2.92$; CI $1.26-6.78 ; p=0.012$ ). The associations between age and hypoglycaemia and between consciousness level and hypoglycaemia were no longer significant upon adjustment for confounding features (Table 5).

Hypoglycaemic subjects were 2.9 times more likely to die than subjects with normoglycaemia, $37.2 \%(n=16 / 43)$ v. $12.8 \%$ $(n=34 / 266)(p<0.001)$. When adjusted for confounding factors (time from last meal, shock, consciousness level, respiratory distress, and medication use before presentation), though hypoglycaemic subjects were 1.8 times more likely to die compared with normoglycaemic subjects, this was no longer significant ( $95 \%$ CI 0.70 - 4.59; $p=0.226$ ). This relationship and other factors associated with dying among the subjects are shown in Table 6 .

\section{Discussion}

The prevalence of hypoglycaemia depends on the blood glucose cut-off, among other factors and, as expected, the prevalence found in this study was higher than those in other studies where hypoglycaemia was defined at lower blood/plasma glucose levels, ${ }^{[4,6,7,10-12]}$ while it was lower than the prevalence in studies with a higher plasma/blood glucose cut-off for hypoglycaemia. ${ }^{[8,13]}$ In addition, Wintergerst and colleagues ${ }^{[13]}$ in California, USA, and Uleanya et al. ${ }^{[8]}$ in Enugu, Nigeria, studied hypoglycaemia among critically ill children in the paediatric intensive care unit and emergency room, respectively, a subset with a usually higher prevalence of hypoglycaemia, in contrast to the present study which recruited all children presenting to the emergency room, irrespective of the severity of their illness. 
Table 3. Factors associated with hypoglycaemia

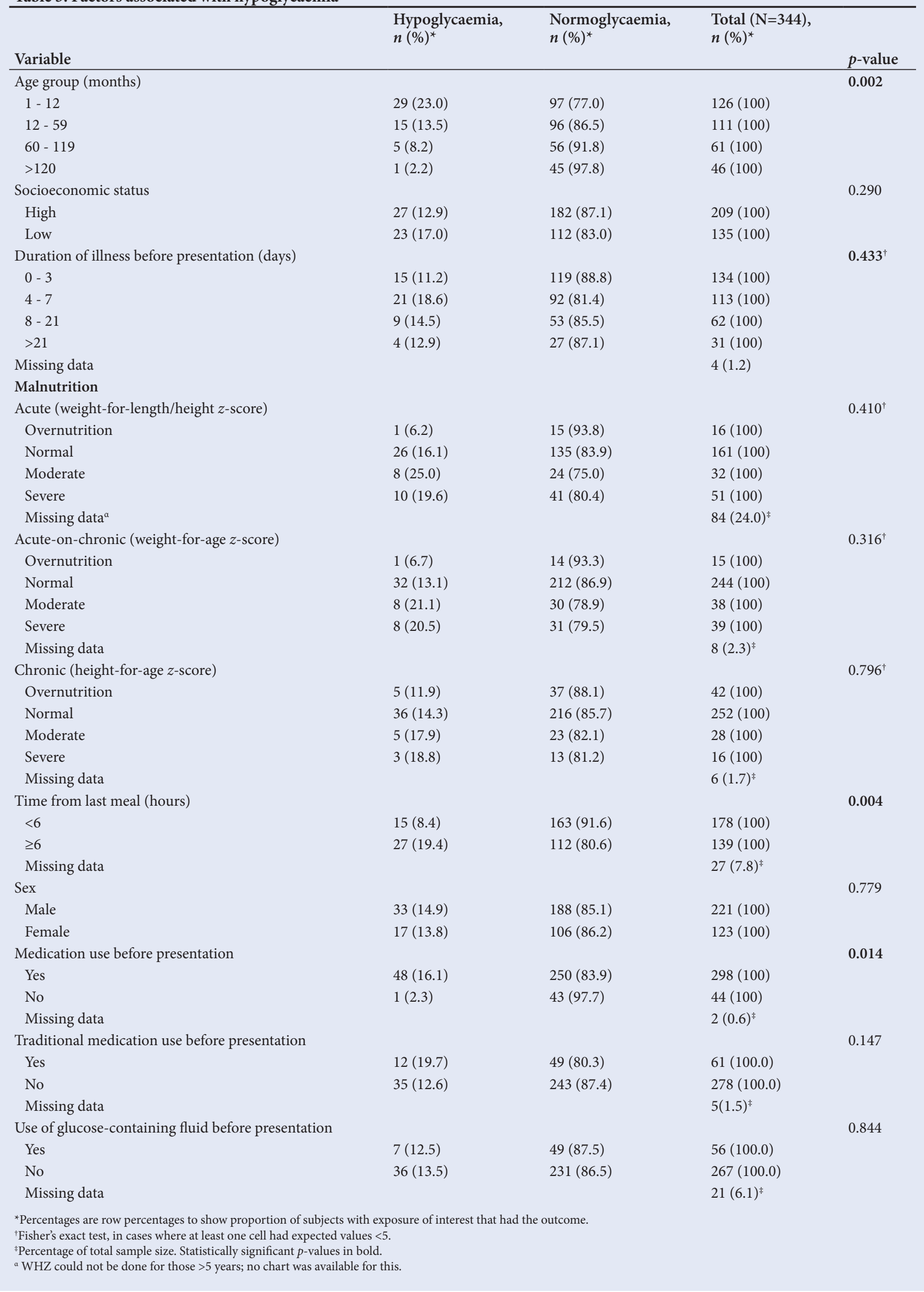


Table 4. Comorbidities and illness severity markers associated with hypoglycaemia

\begin{tabular}{|c|c|c|c|c|}
\hline Variable & $\begin{array}{l}\text { Hypoglycaemia, } \\
n(\%)^{\dagger}\end{array}$ & $\begin{array}{l}\text { Normoglycaemia, } \\
n(\%)^{\dagger}\end{array}$ & $\begin{array}{l}\text { Total } \\
n(\%)^{\dagger}\end{array}$ & $p$-value \\
\hline Convulsion & & & & 0.721 \\
\hline Yes & $9(16.1)$ & $47(83.9)$ & $56(100)$ & \\
\hline No & $41(14.2)$ & $247(85.8)$ & $288(100)$ & \\
\hline Loss of consciousness & & & & 0.006 \\
\hline Yes & $11(29.7)$ & $26(70.3)$ & $37(100)$ & \\
\hline No & $39(12.7)$ & $268(87.3)$ & $307(100)$ & \\
\hline Tachypnoea & & & & 0.12 \\
\hline Yes & $28(12.1)$ & $204(87.9)$ & $232(100)$ & \\
\hline No & $20(18.3)$ & $89(81.7)$ & $109(100)$ & \\
\hline Missing data & & & $3(0.9)^{\ddagger}$ & \\
\hline Respiratory distress & & & & 0.004 \\
\hline Yes & $26(22.4)$ & $90(77.6)$ & $116(100)$ & \\
\hline No & $24(10.8)$ & $198(89.2)$ & $222(100)$ & \\
\hline Missing data & & & $6(1.7)^{\ddagger}$ & \\
\hline Hydration status & & & & $0.002^{\star}$ \\
\hline Not dehydrated & $25(10.7)$ & $209(89.3)$ & $234(100)$ & \\
\hline Moderate dehydration & $19(20.4)$ & $74(79.6)$ & $93(100)$ & \\
\hline Severe dehydration & $6(40.0)$ & $9(60.0)$ & $15(100)$ & \\
\hline Missing data & & & $2(0.6)^{\ddagger}$ & \\
\hline Temperature $\left({ }^{\circ} \mathrm{C}\right)$ & & & & 0.362 \\
\hline$\leq 38.5$ & $35(13.6)$ & $222(86.4)$ & $257(100)$ & \\
\hline$>38.5$ & $15(17.6)$ & $70(82.4)$ & $85(100)$ & \\
\hline Missing data & & & $2(0.6)^{\ddagger}$ & \\
\hline Shock & & & & $0.004^{\star}$ \\
\hline Yes & $7(43.8)$ & $9(56.2)$ & $16(100)$ & \\
\hline No & $43(13.1)$ & $284(86.9)$ & $327(100)$ & \\
\hline Missing data & & & $1(0.3)^{\ddagger}$ & \\
\hline $\mathrm{SpO}_{2}$ & & & & $<0.001$ \\
\hline Hypoxia & $23(32.9)$ & $47(67.1)$ & $70(100)$ & \\
\hline Normal & $21(9.5)$ & $201(90.5)$ & $222(100)$ & \\
\hline Missing data & & & $52(15.1)^{\ddagger}$ & \\
\hline History of fever & & & & 0.007 \\
\hline Yes & $47(17.1)$ & $228(82.9)$ & $275(100)$ & \\
\hline No & $3(4.3)$ & $66(95.7)$ & $69(100)$ & \\
\hline History of fast breathing & & & & 0.013 \\
\hline Yes & $11(27.5)$ & $29(72.5)$ & $40(100)$ & \\
\hline No & $39(12.8)$ & $265(87.2)$ & $304(100)$ & \\
\hline Passage of watery stools & & & & $<0.001$ \\
\hline Yes & $26(26.0)$ & $74(74.0)$ & $100(100)$ & \\
\hline No & $24(9.8)$ & $220(90.2)$ & $244(100)$ & \\
\hline Time of presentation & & & & 0.923 \\
\hline Day (8 am - 3:59 pm) & $12(15.6)$ & $65(84.4)$ & $77(100)$ & \\
\hline Evening (4 - 7:59 pm) & $29(14.6)$ & $170(85.4)$ & $199(100)$ & \\
\hline Night (8 pm - 7:59 am) & $9(13.2)$ & $59(86.8)$ & $68(100)$ & \\
\hline Level of consciousness & & & & $<0.001$ \\
\hline Unconscious & $17(31.5)$ & $37(68.5)$ & $54(100)$ & \\
\hline Conscious & $33(11.5)$ & $255(88.5)$ & $288(100)$ & \\
\hline Missing data & & & $2(0.6)^{\ddagger}$ & \\
\hline Vomiting & & & & 0.746 \\
\hline Yes & $23(15.2)$ & $128(84.8)$ & $151(100)$ & \\
\hline No & $27(14.0)$ & $166(86.0)$ & $193(100)$ & \\
\hline Weakness & & & & 0.759 \\
\hline Yes & $6(16.2)$ & $31(83.8)$ & $37(100)$ & \\
\hline No & $44(14.3)$ & $263(85.7)$ & $307(100)$ & \\
\hline \multicolumn{5}{|c|}{$\begin{array}{l}\text { Statistically significant } p \text {-values in bold. } \\
{ }^{*} \text { Fisher's exact test, in cases where at least one cell had expected value }<5 \text {. } \\
\text { } \text { 'Percentages are row percentages to show proportion of subjects with exposure of interest that had the outcome. } \\
\text { tPercentage of total sample size. }\end{array}$} \\
\hline
\end{tabular}


Table 5. Logistic regression output for factors associated with hypoglycaemia

\begin{tabular}{|c|c|c|c|}
\hline Variable $^{\star}$ & OR & $\mathrm{CI}$ & $p$-value \\
\hline \multicolumn{4}{|c|}{ Age group (months) } \\
\hline $1-12$ & 1.58 & $0.47-5.32$ & 0.463 \\
\hline $12-59$ & 0.89 & $0.25-3.13$ & 0.851 \\
\hline $60-119$ & $1^{+}$ & - & - \\
\hline$\geq 120$ & $0.00^{\ddagger}$ & - & 0.998 \\
\hline \multicolumn{4}{|c|}{ Passage of watery stools } \\
\hline Yes & 2.92 & $1.26-6.78$ & 0.012 \\
\hline No & 1 & - & - \\
\hline \multicolumn{4}{|c|}{$\begin{array}{l}\text { Time interval from last meal } \\
\text { (hours) }\end{array}$} \\
\hline$\geq 6$ & 2.98 & $1.27-6.98$ & 0.012 \\
\hline$<6$ & 1 & - & - \\
\hline \multicolumn{4}{|l|}{$\mathrm{SpO}_{2}$} \\
\hline Hypoxia & 3.1 & $1.39-6.90$ & 0.006 \\
\hline Normal & 1 & - & - \\
\hline \multicolumn{4}{|l|}{ Fever } \\
\hline Yes & 4.85 & $0.62-38.26$ & 0.134 \\
\hline No & 1 & - & - \\
\hline \multicolumn{4}{|c|}{ Consciousness level } \\
\hline Unconscious & 2.36 & $0.95-5.83$ & 0.063 \\
\hline Conscious & 1 & - & - \\
\hline \multicolumn{4}{|c|}{$\begin{array}{l}\text { "Variables used in the logistic regression model were those with } \leq 0.1 \text { significance } \\
\text { with hypoglycaemia at bivariate analysis. For independent variables with a } \\
\text { biological and statistical association with one another, only one of them (the one } \\
\text { with higher significance with hypoglycaemia) was included in the model to avoid } \\
\text { multicollinearity. } \\
\text { 'The group with OR of } 1.00 \text { is the reference group. } \\
\text { "Insufficient sample to determine odds ratio. } \\
\text { sStatistically significant } p \text {-values in bold. }\end{array}$} \\
\hline
\end{tabular}

The prevalence of hypoglycaemia found in the present study was similar to those in two previous studies, though one of those studies defined hypoglycaemia based on different blood glucose cut-off values. ${ }^{[5,9]}$ Okoronkwo et al. ${ }^{[5]}$ studied children $<14$ years old, though at a lower blood glucose cut-off for hypoglycaemia, in contrast to the present study which recruited children up to 17 years old. That study also had more infants and under-5-year-olds compared with the present study $(88.9 \%$ v. $69.3 \%)$. The presence of a higher proportion of younger children ( $<5$ years), who are at greater risk for hypoglycaemia, in their study, as well as the inclusion of children between 14 and 17 years (who have a lower risk of hypoglycaemia) in the current study might have erased the impact of a difference in cut-off values. Hirshberg et al. ${ }^{[9]}$ in a study with similar blood glucose cut-offs ( $\leq 3.3 \mathrm{mmol} / \mathrm{L})$ as in the present study, and among children less than 18 years old but critically ill in the paediatric intensive care unit, found a similar hypoglycaemia prevalence of $9.7 \%$.

The present study found a significant association between age, a time $\geq 6$ hours from last meal to presentation, prior use of medication before presentation, and hypoglycaemia at bivariate analysis level. The finding on the relationship between age and hypoglycaemia agreed with the findings of Okoronkwo et al. ${ }^{[5]}$ and Onyearugha et al. ${ }^{[12]}$ while examining the relationship at a bivariate level in separate studies in Aba, south-east Nigeria, among children aged 1 month to $<14$ years and 1 month to $<16$ years, respectively. Infants and younger children are known to have a higher susceptibility to hypoglycaemia because of a less efficient glucose homeostasis than in older children and adults and due to a small reserve of liver glycogen and muscle protein as well as a relatively higher rate of glucose utilisation owing to their higher brainto-body mass ratio. ${ }^{[2,24]}$ However, this association between age and hypoglycaemia was blunted in the current study when adjustment was made for confounding factors. This lack of association at a multivariate level of analysis might be explained by the presence of confounders such as disease severity markers and existing comorbidities. The higher prevalence of hypoglycaemia in infants and younger children compared with that of older children may not necessarily be due directly to their age but probably a consequence of the severity of their illness and the nature of their comorbidities in comparison with the older subjects. Oyenusi et al. ${ }^{[11]}$ did not find an association between age and hypoglycaemia though this was at a bivariate level.

The higher occurrence of hypoglycaemia among subjects who had not eaten for 6 hours or more can be explained by the time it takes to exhaust the liver glycogen store, which is a ready supply of glucose in children who are starving/fasting. This time has been reported to be $6-8$ hours, ${ }^{[24,25]}$ and as low as 4 hours in infants. ${ }^{[24]}$ Therefore, the average time to exhaustion of the liver glycogen store for a study population will depend on the age structure of the population and will probably be lower if a large proportion of the study population comprises infants and young children. This effect might explain the difference in findings of this study, with regards to fasting time that is significant for development of hypoglycaemia, and those of Okoronkwo et al., ${ }^{[5]}$ and Onyearugha et al., ${ }^{[12]}$ both studies having a greater proportion of infants and younger children and reporting that hypoglycaemia was significantly associated with a time from last meal $\geq 4$ hours; and those of Elusiyan et al., ${ }^{[6]}$ Oyenusi et al. ${ }^{[11]}$ and Osier et al., ${ }^{[7]}$ in which a time $>12$ hours from the last meal significantly predisposed to hypoglycaemia.

The greater occurrence of hypoglycaemia among subjects who had received medications prior to presentation might have some bearing on disease severity, as the subjects with severe illness are more likely to use self-medications before presentation and are also more likely to have hypoglycaemia. In the current study, there was no association between use of traditional medication before presentation and hypoglycaemia, in contrast to the finding by Okoronkwo et al. ${ }^{[5]}$ in a similar study.

The lack of association between severe malnutrition and hypoglycaemia in the present study may be because the subjects with severe malnutrition had the visible severe wasting variety, which is known to have less fatty infiltration of the liver than the variety with nutritional oedema. ${ }^{[26]}$ Fatty infiltration of the liver which occurs in severe malnutrition has been shown to result in glycogen and gluconeogenic substrate depletion, thus predisposing to hypoglycaemia. ${ }^{[27]}$ This lack of association between severe malnutrition and hypoglycaemia contrasts with the finding of Osier et $a l^{[7]}$ in Kenya that severely malnourished subjects had a 1.5 times higher chance of developing hypoglycaemia compared with well-nourished subjects.

In relation to comorbidities and markers of severe illness, the current study found that hypoglycaemia was associated with a history of loss of consciousness, being unconscious at presentation, respiratory distress, shock and hypoxia. A history of fever, fast breathing and passage of watery stools were each associated with hypoglycaemia at a bivariate level. Similarly, Okoronkwo et al. ${ }^{[5]}$ in Nigeria and Osier et al..$^{[7]}$ in Kenya demonstrated an association between loss of consciousness and hypoglycaemia. Loss of consciousness is one of the neuroglycopenic symptoms of hypoglycaemia which results from the effect of glucose decline in the brain. ${ }^{[2,24]}$ Osier et al. ${ }^{[7]}$ also found an association between respiratory distress and hypoxia, respectively and hypoglycaemia. 
Table 6. Factors influencing illness outcome with emphasis on plasma glucose at presentation

\begin{tabular}{|c|c|c|c|c|c|c|}
\hline Factors influencing outcome ${ }^{\star}$ & $\begin{array}{l}\text { Died, } \\
n(\%)^{\dagger}\end{array}$ & $\begin{array}{l}\text { Discharged/alive, } \\
n(\%)^{\dagger}\end{array}$ & $\begin{array}{l}\text { Total, } \\
N(\%)^{\dagger}\end{array}$ & $p$-value & aOR $(95 \% \mathrm{CI})$ & $\begin{array}{l}p \text {-value for } \\
\text { aOR }\end{array}$ \\
\hline Glycaemic level & & & & $<0.001$ & & \\
\hline Hypoglycaemia & $16(37.2)$ & $27(62.8)$ & $43(100)$ & & $1.79(0.70-4.59)$ & 0.226 \\
\hline Normoglycaemia & $34(12.8)$ & $232(87.2)$ & $266(100)$ & & & \\
\hline Missing data & & & $35(10.2)^{\ddagger}$ & & & \\
\hline Time from last meal & & & & 0.054 & & \\
\hline$<6$ hours & $17(10.9)$ & $139(89.1)$ & $156(100)$ & & & \\
\hline$\geq 6$ hours & $25(18.9)$ & $107(81.1)$ & $132(100)$ & & $1.2(0.55-2.60)$ & 0.645 \\
\hline Missing data & & & $56(16.3)^{\ddagger}$ & & & \\
\hline Consciousness level & & & & $<0.001$ & & \\
\hline Conscious & $27(10.5)$ & $230(89.5)$ & $257(100)$ & & & \\
\hline Unconscious & $23(46.0)$ & $27(54.0)$ & $50(100)$ & & $3.90(1.64-9.24)$ & 0.002 \\
\hline Missing data & & & $37(10.8)^{\ddagger}$ & & & \\
\hline Respiratory distress & & & & $<0.001$ & & \\
\hline No & $15(7.6)$ & $183(92.4)$ & $198(100)$ & & & \\
\hline Yes & $35(33.0$ & $71(67.0)$ & $106(100)$ & & $3.66(1.68-7.96)$ & 0.001 \\
\hline Missing data & & & $40(11.6)^{\ddagger}$ & & & \\
\hline Shock & & & & $<0.001$ & & \\
\hline No & $41(14.0)$ & $252(86.0)$ & $293(100)$ & & & \\
\hline Yes & $9(60.0)$ & $6(40.0)$ & $5(100)$ & & $2.58(0.69-9.66)$ & 0.159 \\
\hline Missing data & & & $36(10.5)^{\ddagger}$ & & & \\
\hline Medication use before presentation & & & & 0.014 & & \\
\hline No & $01(2.6)$ & $38(97.4)$ & $39(100)$ & & & \\
\hline Yes & $48(17.9)$ & $220(82.1)$ & $268(100)$ & & $3.37(0.42-27.02)$ & 0.252 \\
\hline Missing data & & & $37(10.8)^{\ddagger}$ & & & \\
\hline \multicolumn{7}{|c|}{$\begin{array}{l}\text { OR = adjusted odds ratio; } \mathrm{CI}=\text { confidence intervals. } \\
{ }^{*} \text { The table illustrates the association between hypoglycaemia and outcome of hospitalisation, adjusted for the effe } \\
\text { independent variables were selected if they had a significant association of } p \leq 0.1 \text { with both hypoglycaemia and il } \\
\text { with a biological and statistical association with one another, only one of them (the one with higher significance } \\
\text { multicollinearity. } \\
\text { 'Percentages are row percentages to show proportion of subjects with exposure of interest that had the outcome. } \\
{ }^{\text {} P e r c e n t a g e ~ o f ~ t o t a l ~ s a m p l e ~ o f ~ n o r m o g l y c a e m i c ~ a n d ~ h y p o g l y c a e m i c ~ s u b j e c t s ~}(N=344) \text {. } \\
\text { 'Statistically significant } p \text {-values in bold. }\end{array}$} \\
\hline
\end{tabular}

Fever is an inflammatory response which may be present owing to primary illness and may lead to higher peripheral glucose utilisation, thus contributing to the development of hypoglycaemia. ${ }^{[28]}$ The association of hypoglycaemia with watery stools and shock is probably due to a failure of gluconeogenesis. ${ }^{[29]}$ Bennish et al. ${ }^{[29]}$ demonstrated an inadequately low rise in gluconeogenic substrates in diarrhoeal and dehydrated children with hypoglycaemia despite an appropriate elevation in insulin counter-regulatory hormones - glucagon and epinephrine - which seemed to suggest that the pathogenesis of hypoglycaemia in this subset of children might be failure of glucogenesis. History of fast breathing might be a feature of the primary illness or driven by the elaboration of epinephrine as part of the body's response to hypoglycaemia.

Hypoglycaemic subjects in the current study were three times more likely to die than normoglycaemic subjects. This finding agreed with those of Nigerian studies by Okoronkwo et al., ${ }^{[5]}$ Elusiyan et al., ${ }^{[6]}$ Jaja et al.,. ${ }^{[10]}$ Oyenusi et al., ${ }^{[11]}$ Onyearugha et al. ${ }^{[12]}$ and Uleanya et al. ${ }^{[13]}$ which studied all children ${ }^{[5,6,10-12]}$ and critically ill children ${ }^{[13]}$ with varying upper age limits between 10 and 16 years old but all excluding neonates, admitted into various children's emergency facilities. This finding also agreed with those from Sambany et al. ${ }^{[4]}$ in Madagascar among children aged 1 month to 15 years and Osier et al. ${ }^{[7]}$ in Kenya among children including neonates admitted into paediatric wards. All these studies demonstrated varying levels of significantly higher mortality rates among hypoglycaemic subjects compared with euglycaemic ones. However, upon adjusting for confounding factors, the association between hypoglycaemia and mortality in this study was no longer statistically significant. The blunting of this association might be explained by the influence of confounders such as illness severity markers and patients' comorbidities on the relationship between hypoglycaemia and illness outcome. These illness severity markers were significantly associated with hypoglycaemia as well as with dying in the subjects and might be the reason why a higher proportion of hypoglycaemic subjects died than the normoglycaemic.

Our study only determined association and not risk factors for hypoglycaemia owing to its cross-sectional design. Also, we did not determine the impact of glucose variability on disease outcome as only the plasma glucose value at the point of admission was considered. Finally, our study did not determine the association between use of specific medications before presentation and hypoglycaemia, which would have added more value to the findings.

\section{Conclusion}

Hypoglycaemia is a common complication of childhood illnesses and should be suspected especially if the duration from last meal to presentation is $\geq 6$ hours, and there is presence of watery stools or hypoxia. It may also be suspected in the presence of loss of 
consciousness or a history thereof, respiratory distress, dehydration or shock, a history of fever or fast breathing, and use of medications before presentation. Hypoglycaemia increases the risk of dying in ill children, though this association was lost at multivariable analysis. We therefore recommend that ill children, especially those with the above profile, be promptly and routinely screened for hypoglycaemia. The provision and use of glucometers as well as properly equipped side laboratories for children's emergency rooms in low-income-country settings will help to achieve this and save children's lives.

\section{Declaration. None.}

Acknowledgements. We thank Prof. Barry Pizer of the Department of Oncology/Haematology, Alder Hey Children's Hospital NHS Foundation Trust, Liverpool, United Kingdom, the corresponding author's work supervisor, for reviewing the draft article; Mr Chibuike Esonwune, Assistant Chief Medical Laboratory Scientist at the Chemical Pathology Laboratory of NAUTH, Nnewi, who analysed the blood samples; Drs Ijezie, Ofojebe and Ifiora and our House Officers in Paediatrics NAUTH, who helped with data collection.

Author contributions. All authors contributed to research conceptualisation, data collection and analysis. NCA developed the manuscript and the other authors read, revised and approved it.

Funding. None.

Conflicts of interest. None.

1. Mayes PA, Bender DA. Gluconeogenesis and control of the blood glucose. In: Murray RK, Granner DK, Mayes PA, Rodwell VW, editors. Harper's Illustrated Biochemistry. 26th ed. New York: Lange Medical Books/McGraw-Hill; 2000: pp 153-162.

2. Sperling MA. Hypoglycemia. In: Kliegman RM, Stanton BF, St Geme III JW, Schor NF, Behrman RE, editors. Nelson Textbook of Pediatrics. 20th ed. Philadelphia: Elsevier; 2016: pp 773-788.

3. Haymond MW. Diarrhoea, malnutrition, euglycaemia and fuel for thought. N Engl J Med 1990;322:1390-1391. https://doi.org/10.1056/ nejm199005103221911

4. Sambany E, Pussard E, Rajaonarivo C, Raobijaona H, Barennes H. Childhood dysglycaemia: Prevalence and outcome in a referral hospital. PLoS ONE 2013; 8(5):e651193. https://doi.org/10.1371/journal.pone.0065193

5. Okoronkwo NC, Eke FU, Oruamabo RS. Hypoglycaemia among children presenting to emergency paediatrics unit of Abia State University Teaching Hospital, Aba, Nigeria. Int J Med Health Sci 2013;2:410-418.

6. Elusiyan JB, Adejuyigbe EA, Adeodu OO. Hypoglycaemia in a Nigerian paediatric emergency ward. J Trop Pediatr 2006;52(2):96-102. https://doi. org/10.1093/tropej/fmi068

7. Osier FHA, Berkley JA, Ross A, Sanderson F, Mohammed S, Newton CRJC. Abnormal blood glucose concentrations on admission to a rural Kenyan district hospital: Prevalence and outcome. Arch Dis Child 2003;88(7):621-625. https://doi.org/10.1136/adc.88.7.621

8. Wintergerst KA, Buckingham B, Gandrud L, Wong BJ, Kache S, Wilson DM. Association of hypoglycemia, hyperglycemia and glucose variability with morbidity and death in paediatric intensive care unit. Pediatrics 2006;118(1):173-179.
9. Hirshberg E, Larsen G, Van Duker H. Alterations in glucose homeostasis in the pediatric intensive care unit. Hyperglycemia and glucose variability are associated with increased mortality and morbidity. Pediatr Crit Care Med 2008;9(4):361-366. https://doi.org/10.1097/pcc.0b013e318172d401

10. Jaja T, Nte AR, Ejilemele AA. Post-neonatal hypoglycaemia and paediatric emergency room admissions: a study in the University of Port Harcourt Teaching Hospital. Nigerian Health J 2011;11(1):19-22.

11. Oyenusi EE, Oduwole AO, Oladipo OO, Njokanma OF, Esezobor CI. Hypoglycaemia in children aged 1 month to 10 years admitted to the Children's Emergency Centre of Lagos University Teaching Hospital, Nigeria. S Afr J Child Health 2014;8(3):107-111. https://doi.org/10.7196/SAJCH.737

12. Onyearugha CN, George IO. Incidence of hypoglycaemia in a paediatric emergency ward in Nigeria. Br J Med Res 2015;10(7):1-8. https://doi. org/10.9734/BJMMR/2015/13339

13. Uleanya ND, Aniwada EC, Nwokoye IC, Ndu IK, Eke CB. Relationship between glycemic levels and treatment outcome among critically ill children admitted into emergency room in Enugu. BMC Pediatr 2017;17:126. https:// doi.org10.1186/s12887-017-0879-8

14. Herold JM. Surveys and sampling. In: Gregg MB, editor. Field Epidemiology. 3rd ed. New York: Oxford University Press; 2008: pp 97-115.

15. World Health Organization. Handbook: IMCI integrated management of childhood illness. Geneva: WHO; 2005.

16. World Health Organization. The treatment of diarrhoea: A manual for Physicians and other Senior Health Workers. 4th rev. Geneva: World Health Organization; 2005: p 8.

17. World Health Organization. Pulse Oximetry Training Manual. Geneva: World Health Organization; 2011: p 8.

18. Drayna PC, Gorelick MH. Evaluation of the sick child in the office and clinic. In: Kliegman RM, Stanton BF, St Geme III JW, Schor NF, Berhman RE, editors. Nelson Textbook of Pediatrics. 20th ed. Philadelphia: Elsevier; 2016:474-476.

19. Stenson B, Cunningham S. Babies and Children. In: Innes JA, Dover AR Fairhurst K, editors. Macleod's Clinical Examination. 14th ed. Edinburgh: Elsevier; 2018: pp 298-318.

20. Oyedeji GA. Socio-economic and cultural background of hospitalised children in Ilesha. Niger J Paediatr 1985;12:111-117.

21. World Health Organization. Global Database on Child Growth and Malnutrition. https://www.who.int/nutgrowthdb/about/introduction/en/ index $5 . h$ tml (accessed 24 November 2019).

22. Pagana KD, Pagana TJ. Glucose, Blood (Blood sugar, Fasting Blood Sugar [FBS]). In: Pagana KD, Pagana TJ, editors. Mosby's Manual of Diagnostic and Laboratory Tests. 4th ed. St Louis, Missouri: Mosby; 2010:267-273.

23. Mayer-Davis EJ, Kahkoska AR, Jefferies C, et al. ISPAD Clinical Practice Consensus Guidelines 2018: Definition, epidemiology, and classification of diabetes in children and adolescents. Pediatr Diabetes 2018;19 (Suppl. 27):719. https://doi.org/10.1111/pedi.12773

24. Langdon DR, Stanley CA, Sperling MA. Hypoglycaemia in the toddler and child. In: Sperling MA, editor. Pediatric Endocrinology. 4th ed. Philadelphia: Saunders; 2014: pp 920-955.

25. The Barbara Bush Children's Hospital, Maine Medical Centre. Fasting study for the evaluation of hypoglycemia in pediatric patients: Inpatient unit management clinical guideline. 2007.

26. Reddy V. Protein-energy malnutrition. In: Stanfield P, Brueton M, Chan M, Parkin M, Waterston T, editors. Diseases of children in the subtropics and tropics. 4th ed. London: Hodder Education;1991:335-357.

27. Cornblath M, Schwartz R. Disorders of carbohydrate metabolism in infancy. 3rd ed. Boston: Blackwell Scientific Publications;1991:1-53.

28. Miller SI, Wallace RJ Jr, Musher DM, Septimus EJ, Kohl S, Baughn RE. Hypoglycaemia as a manifestation of sepsis. Am J Med 1980;68(5):649-654. https://doi.org/10.1016/0002-9343(80)90250-8

29. Bennish ML, Azad AK, Rahman O, Philips RE. Hypoglycemia during diarrhea in childhood - prevalence, pathophysiology and outcome. N Engl J Med 1990;322(19):1357-1363. https://doi.org/10.1056/nejm199005103221905

Accepted 5 August 2020 